\title{
Nigella sativa L. Seed Extract Modulates the Neurotransmitter Amino Acids Release in Cultured Neurons In Vitro
}

\author{
Tarek El-Naggar, ${ }^{1}$ María Pilar Gómez-Serranillos, ${ }^{1}$ Olga María Palomino, ${ }^{1}$ \\ Carmen Arce, ${ }^{2}$ and María Emilia Carretero' \\ ${ }^{1}$ Pharmacology Department, Faculty of Pharmacy, Universidad Complutense de Madrid, Plaza Ramón y Cajal s/n, \\ 28040 Madrid, Spain \\ ${ }^{2}$ Biochemistry and Molecular Biology Department, Faculty of Pharmacy, Universidad Complutense de Madrid, \\ Plaza Ramón y Cajal s/n, 28040 Madrid, Spain \\ Correspondence should be addressed to María Pilar Gómez-Serranillos, pserra@farm.ucm.es
}

Received 9 December 2009; Revised 22 March 2010; Accepted 19 April 2010

Academic Editor: Mohamed Boutjdir

Copyright () 2010 Tarek El-Naggar et al. This is an open access article distributed under the Creative Commons Attribution License, which permits unrestricted use, distribution, and reproduction in any medium, provided the original work is properly cited.

Nigella sativa L. (NS) has been used for medicinal purposes since ancient times. This study aimed to investigate the cytotoxicity of NS dry methanolic extract on cultured cortical neurons and its influence on neurotransmitter release, as well as the presence of excitatory (glutamate and aspartate) and inhibitory amino acids (gamma-aminobutyric acid—GABA— and glycine) in NS extract. Cultured rat cortical neurons were exposed to different times and concentrations of NS dry methanolic extract and cell viability was then determined by a quantitative colorimetric method. NS did not induce any toxicity. The secretion of different amino acids was studied in primary cultured cortical neurons by high-performance liquid chromatography (HPLC) using a derivation before injection with dansyl chloride. NS modulated amino acid release in cultured neurons; GABA was significantly increased whereas secretion of glutamate, aspartate, and glycine were decreased. The in vitro findings support the hypothesis that the sedative and depressive effects of NS observed in vivo could be based on changes of inhibitory/excitatory amino acids levels.

\section{Introduction}

Nigella sativa L. (NS) is a vegetal specie of the Ranunculaceae family, commonly known as "black cumin seed", "neguilla" or "ajemuz", that is widely cultivated in the Mediterranean region. Its seeds have played an important role over the years in ancient Islamic system of herbal medicine and in Spain, where they have been traditionally used in folk medicine. NS seeds have shown several therapeutic effects such as prevention of cancer [1], antihypertensive effect [2], antiinflammatory, analgesic [3], and antihistaminic [4] actions. These properties have been proved and documented by recent research [5-10].

The volatile oil from this plant presents a relaxant action on different smooth muscles [11] and tracheal muscles of guinea pigs [12]. There is evidence of anticonvulsant and antioxidant effects against pentylenetetrazol-induced kindling in mice [13]. In addition, it is more potent as an anticonvulsant agent than valproate [13]. Likewise, aqueous extract of this plant suppresses penicillin-induced epileptic activity in rats. This anticonvulsant effect is a consequence of selectively altering the monoamine level in different brain regions [14].

In recent works, histopathological changes of neurodegeneration in the frontal cortex and brain stem in neurons after exposition to toluene have been observed [15, 16]. The administration of NS extract and thymoquinone (major component from NS volatile oil) causes morphologic improvement over apoptosis and indicates that NS therapy is useful as a potential treatment of neurodegeneration prevention.

NS seeds composition includes nutritional components such as carbohydrates (glucose, xylose, rhamnose, and arabinose), vitamins as thiamine, riboflavin, pyridoxine, niacin and folic acid [5], mineral elements, and proteins. The NS 
seeds are also a source of calcium, iron and potassium, alkaloids (nigellidine, nigellimine, and nigellicine) [17], 36\%$38 \%$ fixed oil and $0.4 \%-2.5 \%$ essential oil [18]. The fixed oil is mainly composed of unsaturated and essential fatty acids (linoleic acid, followed by oleic acid) [19] whereas the volatile oil has been shown to contain $18.4-24 \%$ thymoquinone and $46 \%$ monoterpenes such as $p$-cymene and pinene $[5,20]$. Thimoquinone, as indicated above, is thought to be the main active component of NS seeds [18] and suppresses itself epileptic seizures in rats [21], while a monodesmosidic triterpene saponin, $\alpha$-hederin, has also been isolated from the extract of NS seeds and proved to exert antitumoral activity [22].

Other active principles are nigellone and nigellidine which contains an indazol nucleus [23]. Three flavonoid glycosides and triterpene saponins were also identified from Nigella sativa, together with four phospholipid classes: phosphatidylcholine phosphatidylethanolamine, phosphatidylserine, and phosphatitdylinositol [24, 25]. In previous studies we demonstrated that aqueous and methanolic extracts of NS seeds exert a potent sedative and depressive effect on CNS and induce analgesia [26]. The effect on CNS resulted in a significant reduction of spontaneous motility, a decrease in normal body temperature and significant analgesic action against hotplate and pressure tests. Body temperature reduction can be interpreted as an index of alteration of various central neurotransmitters; anxiety and sedation are mainly mediated by the GABA-A receptor in the CNS. Since depressant action was confirmed specially for the methanolic extract, we decided to study whether the addition of this methanolic dry extract in cortical neurons culture could exert any influence on the secretion of the excitatory amino acids aspartate (Asp) and glutamate (Glu), and the inhibitory amino acids GABA and glycine (Gly), as well as the presence of these amino acid neurotransmitters in the extract. We also considered its effect on the amino acids secretion when stimulated by a depolarizing agent and its effect on cultured neurons viability.

\section{Results}

2.1. Cell Viability. The viability of the cultured neurons after exposition to NS extract concentrations 2.5, 25, and $250 \mu \mathrm{g} / \mathrm{mL}$ during 15 and 60 minutes are shown in Figure 1. No significant changes were observed on neuronal viability at any assayed concentration. Results are expressed as a percentage with respect to control value (100\% viability).

\subsection{Amino Acids Determination}

2.2.1. Amino Acids Determination in the NS Extract. The amino acids GABA, Gly, Glu, and Asp were measured in NS methanolic extract by HPLC. The results are expressed as pmoles/mg of NS extract (Table 1). The results showed Gly as the most abundant, followed by GABA, Glu, and Asp, respectively. The amino acids content in the extract was subtracted from the total amino acid content measured in the

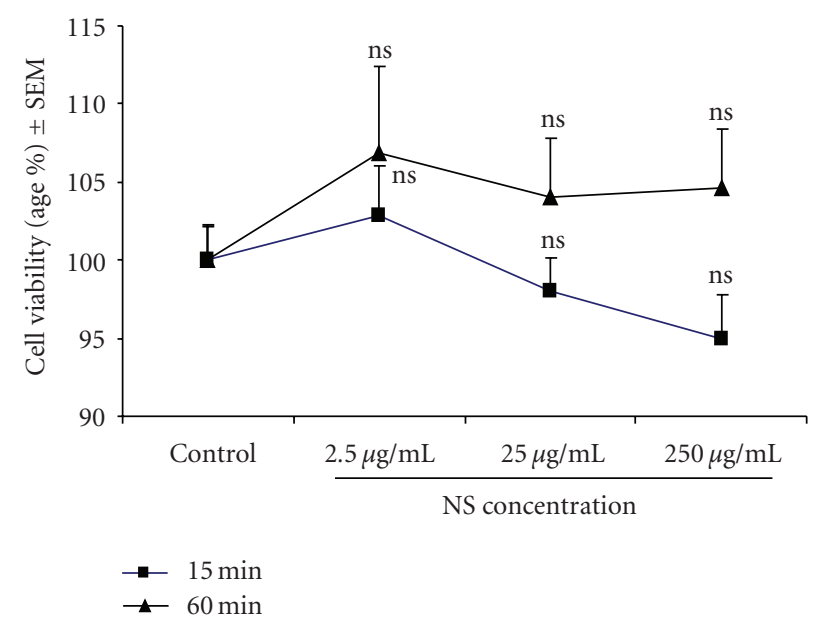

FIGURE 1: Effect of Nigella sativa methanolic extract on neuronal viability measured by MTT assay. The cells were stimulated for 15 and 60 minutes with different concentrations of this extract (2.5, 25 and $250 \mu / \mathrm{mL}$, final concentration). The results are presented as \pm SEM of three independent experiments and statistical analysis resulted in no significant differences when compared with the control group.

cellular medium after neuronal stimulation with NS extract so we can state that the final amino acids content in cell culture is a direct consequence of cell release.

2.2.2. Amino Acids Release in Presence of NS Extract. The release of the four amino acids after stimulation with the chosen nontoxic concentrations of NS extract $(2.5,25$, and $250 \mu \mathrm{g} / \mathrm{mL}$ ) showed a diminished secretion response that was statistically significant $(P<.05$ for Gly and Glu; $P<.01$ for GABA; $P<.001$ for Asp) after 15 minutes of incubation with respect to control (neuronal cells stimulated with normal Locke medium during the same period of time and considered as 100\% secretion) (Figures 2, 3, 4, and 5). Gly and Asp release was reduced in a dose dependent manner; Glu and GABA showed a tendency to retrieve control values, although their secretion was lower than control. This fall of aminoacids release is greater for higher extract concentration except for Glu and GABA, which showed a tendency to recuperation to control values at the same time (Figure 2). The HPLC analysis revealed the same behavior for all the amino acids, with the exception of GABA, after treatment with NS extract during 60 minutes. The increased presence of this amino acid was statistically significant for 25 and $250 \mu \mathrm{g} / \mathrm{mL}$ NS extract.

2.2.3. Amino Acid Release Evoked by $60 \mathrm{mM} \mathrm{KCl}$. In order to know the response to a depolarizing agent, cortical neurons were stimulated with NS extract at the indicated concentrations, during 15 and 60 minutes previous to depolarization with $60 \mathrm{mM} \mathrm{KCl}$ (Figures 6 and 7).

The neurons treated with NS extract during 15 minutes and subsequently stimulated with $\mathrm{KCl}$ showed a dosedependent decrease in amino acids secretion with respect 
TABLE 1: Amino acids composition of methanolic extract of Nigella sativa. The results are expressed as pmoles of each amino acid by mg of methanolic extract, prepared under the conditions indicated in experimental procedures.

\begin{tabular}{lcccc}
\hline Amino acid & Asp & Glu & Gly & GABA \\
\hline pmoles/mg NS & $234.64 \pm 8.03$ & $345.26 \pm 11.82$ & $1943.28 \pm 51.8$ & $396.24 \pm 13.59$ \\
Methanolic extract & & &
\end{tabular}

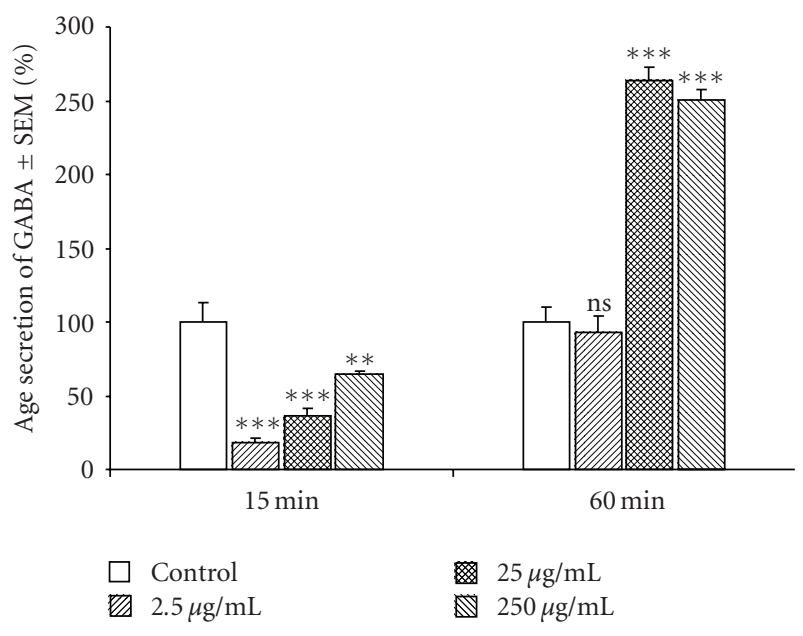

Figure 2: Effect produced by different concentrations $(2.5,25$, and $250 \mu \mathrm{g} / \mathrm{mL}$ ) of methanolic extract of Nigella sativa on GABA release from cortical neurons. The cells were stimulated for 15 and 60 minutes with each concentration. The values are expressed as a percentage of secretion with respect to basal value (100\%). Statistical significances were calculated with respect to the corresponding control at its respective time points: ${ }^{* *} P<.01$; ${ }^{* * *} P<.001$.

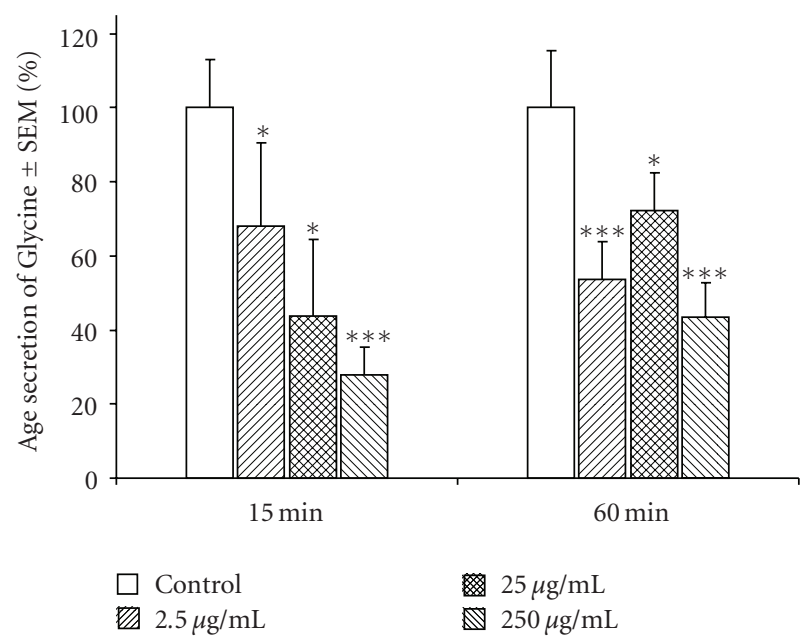

Figure 3: Effect produced by different concentrations (2.5, 25, and $250 \mu \mathrm{g} / \mathrm{mL}$ ) of methanolic extract of Nigella sativa on Glycine release from cortical neurons. The cells were stimulated for 15 and 60 minutes with each concentration. The values are expressed as a percentage of secretion with respect to basal value ( $100 \%)$. Statistical significances were calculated with respect to the corresponding control at its respective time points: ${ }^{*} P<.05$ and ${ }^{* * *} P<.001$.

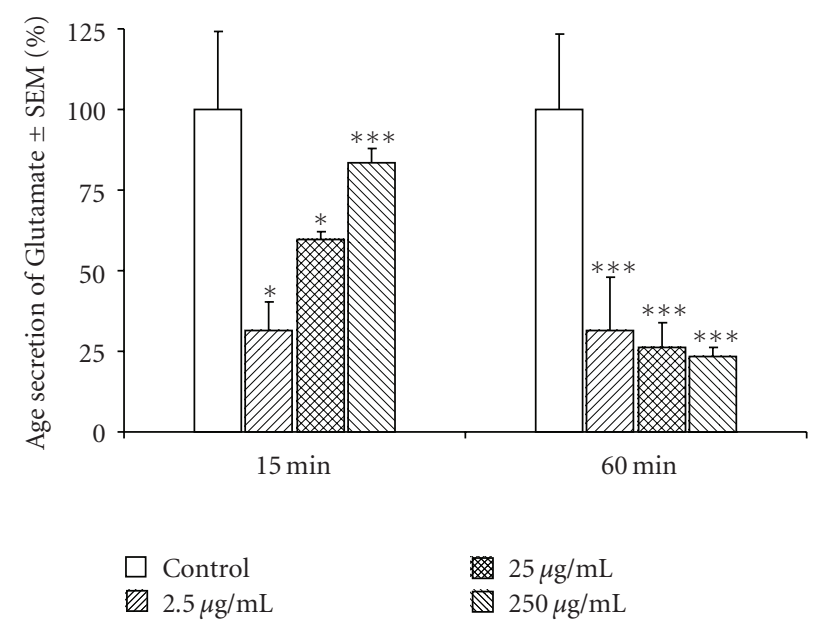

FIGURE 4: Effect produced by different concentrations $(2.5,25$, and $250 \mu \mathrm{g} / \mathrm{mL}$ ) of methanolic extract of Nigella sativa on Glutamate release from cortical neurons. The cells were stimulated for 15 and 60 minutes with each concentration. The values are expressed as a percentage of secretion with respect to basal value (100\%). Statistical significances were evaluated with respect to the corresponding control at its respective time points: ${ }^{*} P<.05$ and ${ }^{* * *} P<.001$.

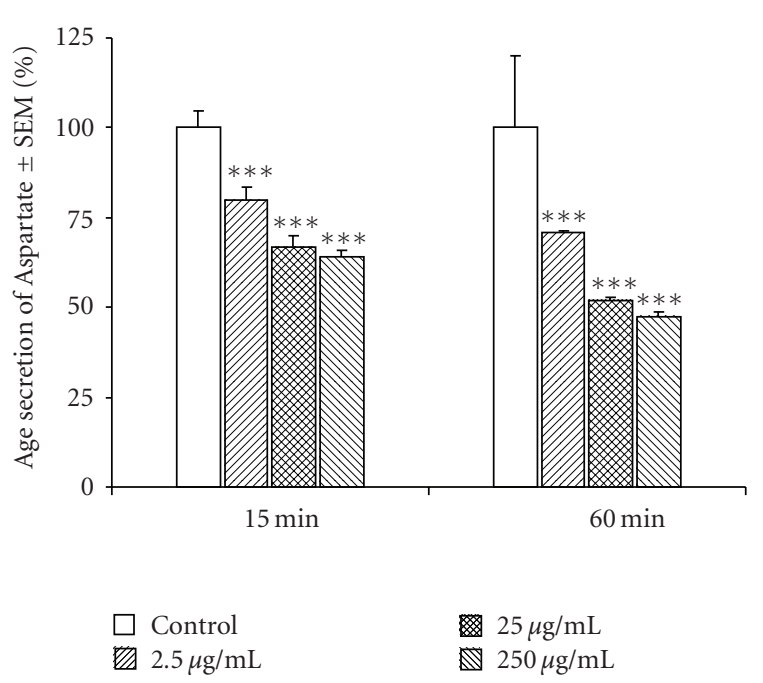

FIGURE 5: Effect produced by different concentrations (2.5, 25, and $250 \mu \mathrm{g} / \mathrm{mL}$ ) of methanolic extract of Nigella sativa on Aspartate release from cortical neurons. The cells were stimulated for 15 and 60 minutes with each concentration. The values are expressed as a percentage of secretion with respect to basal value (100\%). Statistical significances were calculated with respect to the corresponding control at its respective time points: ${ }^{* * *} P<.001$. 


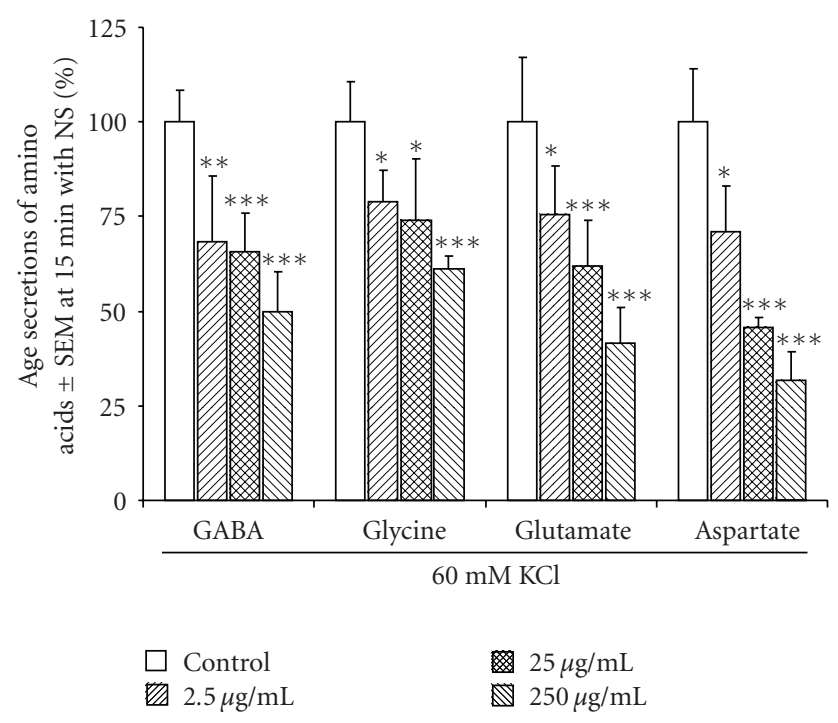

FIGURE 6: Secretion of amino acid neurotransmitters evoked by $60 \mathrm{mM} \mathrm{KCl}$, measured in cortical neurons culture. The cells were previously treated with methanolic extract of Nigella sativa for 15 minutes. The values are expressed as a percentage of secretions with respect to basal value (100\%). Statistical significances were calculated with respect to the corresponding control at its respective time points: ${ }^{*} P<.05,{ }^{* *} P<.01$ and ${ }^{* * *} P<.001$.

to control value (neuronal cells stimulated with Locke medium), which was considered as $100 \%$. The observed behaviour was more relevant for Glu and Asp at 25 and 250 $\mu \mathrm{g} / \mathrm{mL}$ than for GABA and Gly under the same conditions (Figure 6).

Measurement of secretion mediated by $\mathrm{KCl}$ during 60 minutes revealed an inhibition of the liberation of these neurotransmitters. In this case, only GABA and Glu were released in a dose-dependent manner (Figure 7).

\section{Discussion}

The aim of the study was to determine the effects of NS methanolic extract on the release of neurotransmitter amino acids by measuring their concentrations in the culture media using HPLC precolumn derivatization technique. Three concentrations of NS extract $(2.5,25$, and $250 \mu \mathrm{g} / \mathrm{mL})$ and two time points ( 15 and $60 \mathrm{~min}$ ) for the determination of the effects were used. This is a preliminary study which shows that exposure of the cultured neurons have a modulatory effect on the release and contents of these aminoacids.

The 3-(4,5-dimethylthiazol-2-yl)-2,5diphenyltetrazolium bromide (MTT) assay was employed to estimate the cells viability when neurons were treated with NS extract. The three concentrations of dry methanolic extract used in our study did not affect cellular respiratory capacity at any of the two periods of time considered. These results allowed us to consider the adequate approach to the study of amino acid secretion in the conditions selected and to confirm the innocuous characteristics of the chosen extract concentrations.

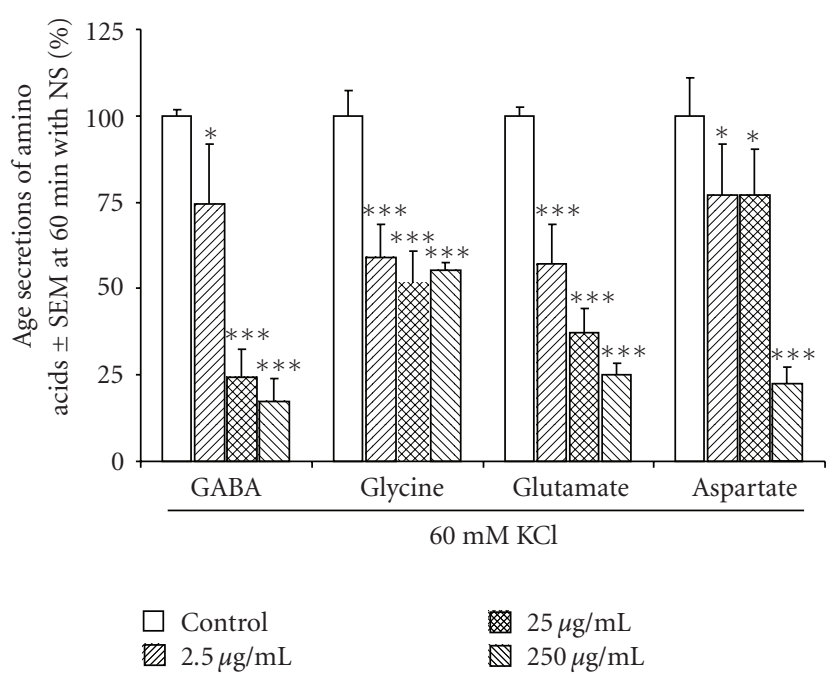

Figure 7: Secretion of amino acid neurotransmitters evoked by $60 \mathrm{mM} \mathrm{KCl}$, measured in cortical neurons culture. The cells were previously treated with methanolic extract of Nigella sativa for 60 minutes. The values are expressed as a percentage of secretions with respect to basal value (100\%). Statistical significances were calculated with respect to the corresponding control at its respective time points: ${ }^{*} P<.05$ and ${ }^{* * *} P<.001$.

Our previous in vitro findings support the hypothesis that the sedative and depressive effects of Nigella sativa (NS) observed in vivo [26], could be based on changes of inhibitory/excitatory amino acids levels. Several authors attribute the sedative effects of different plant extracts (Valeriana officinalis L., Scutellaria lateriflora L.) [27, 28] to its endogenous GABA concentration, although they also hypothesize that there exist other components of the vegetal extracts with benzodiazepine-like effects that may account for their in vivo effects. The aim of our research was to determine whether these substances that are present in the NS extract could mediate the specific effects previously observed in vivo through the secretion of Asp, Glu, GABA, and Gly.

First of all, the presence and content of the four amino acids in the extract was analyzed by HPLC, showing a major presence of inhibitory amino acids (Gly and GABA) (Table 1).

Then, the cell amino acids release was assayed after addition of several concentrations of NS extract to cultured neurons during two different periods of time (15 and 60 minutes). The aim of this approach was to observe whether neuronal secretion could be modified depending on the exposition time. High secretion of GABA was observed after 60 minutes' contact with NS extract at 25 and $250 \mu \mathrm{g} / \mathrm{mL}$. This time is close to the one that allowed the maximum effect in our in vivo study, close to 40 minutes [26].

Under these conditions, neuronal GABA was liberated to the medium. Similar results have been observed when high GABA concentrations are present in an aqueous extract of Valeriana officinalis root which induced in vitro liberation 
of $\left[{ }^{3} \mathrm{H}\right] \mathrm{GABA}$ in rat synaptosomes by reversal of the GABA carrier and inhibition of its reuptake [27]. Subsequently, it was described the same behavior for Scutellaria lateriflora L. [28]. Both plants are widely prescribed as sedative/anxiolytic ones. As the GABA presence in the methanolic extract of NS was confirmed with our results, it is possible to assume that a high level of GABA in the medium during cellular incubation and a longer period of exposition at this one could exert the same effect above described.

Recent findings suggest that NS protects from induced generalized epilepsy in rats by selectively altering the monoamine level in different brain regions [14]. This study pointed that NS possibly facilitates the inhibitory activity of the GABAergic system through a competitive agonist action in the benzodiazepine (BZD) site of the GABA receptor as well as the involvement of dopaminergic and noradrenergic system. The confirmed presence of GABA in the methanolic extract could be directly related to its conduct over the GABA receptor and this could explain the potent sedative and depressive effect on CNS as previously reported. Moreover, the important presence of Gly in the extract could be also related to its inhibitory action. The binding of both neurotransmitters to their receptors on the neuronal membrane induces hyperpolarization that could be responsible for a significantly lower secretion of amino acids with respect to control values. In addition to this, our results showed a decrease in neuronal excitatory activity derived from a diminished Asp and Glu secretion, specially the second one. These actions could also be concurrent with the in vivo observed effects.

Our results show the behavior of the cortical neurons and confirm what we expected from the previous study performed in vivo. Likewise the methanolic extract composition is able to mediate in the neuronal amino acids release. In this case, the NS extract had an influence on neuronal transmission because it modifies the neurotransmitter amino acids release.

Depolarization of neuronal cells by application of high $\mathrm{K}+$ concentration $(60 \mathrm{mM} \mathrm{KCl})$ induced a diminished amino acid release in both periods of time assayed. This diminished release was similar to nondepolarizing secretion except for GABA which also diminished its secretion. Although multiple mechanisms of neurotransmitter release evoked by elevated extracellular $\mathrm{K}+$ may be involved $[29,30]$, we consider that the effect of NS extract over neuronal cells produces a drop in the transmission and is responsible for of the inhibitory effect indicated above. A possible action of NS extract over L-Type Calcium channels or an opening on potassium channels had been suggested by others authors [31-35], and it could contribute to the relaxant activities of this plant. Furthermore, its possible effect over these channels could persist even after the extract was eliminated from the medium before depolarization.

With respect to GABA secretion, the only amino acid which differs in its behavior with respect to nondepolarizing liberation, the diminished secretion may derivate from the membrane transporter-reversal for GABA above suggested. In our study, we have considered the possibility that the GABA carrier had been previously affected by the presence of NS extract during 15 or 60 minutes, inhibiting GABA reuptake and favouring its liberation from neurons. Other authors [30] have concluded that extracellular $\mathrm{K}+(50 \mathrm{mM}$ $\mathrm{KCl}$ ) provokes $\mathrm{GABA}$ release by reversal transporter of GABA. In our case, we observed a diminished liberation that could be justified by the previous loss of cellular GABA content as the neurons had been treated with the NS extract.

In conclusion, this study suggests a sedative effect of NS methanolic extract by modification of neurotransmitter amino acids release, because the NS extract may induce an important release of GABA and Gly in the cultured neurons medium and therefore, exert an increase in the agonist action over their receptors. The results explain the sedative and depressive effects observed in vivo by an increase in inhibitory amino acids at the synaptic terminals. Even more, this effect is complemented with a possible decrease of excitatory transmission, as it has been demonstrated in vitro and could contribute to inhibitory response.

\section{Experimental Procedures}

4.1. Materials. Minimum Essential Eagle's Medium (EMEM) was obtained from Bio-Whittaker, and Foetal Bovine Serum (FBS) and Horse Serum (HS) were procured from Sera-Lab (Sussex, England). Standards of Glutamate, Aspartate, GABA and Glycine were purchased from Sigma (St. Louis, Mo, USA). Reagents and solvents for HPLC were Triethylamine from Sigma (St. Louis, Mo, USA), Acetic acid and Methanol ultra gradient grade from Merck (Darmstadt, Germany). Other chemicals were reagent grade products from Merck (Darmstadt, Germany).

Distilled water used for the preparation of buffers and standards was deionized with Milli-Q purification system. Syringe filters Millex-GV were obtained from Millipore (Milford, MA, USA).

Membrane filters $(0.45 \mu \mathrm{m}$ pore size $)$ from Tecknochroma (Barcelona, Spain) were used for filtration of the mobile phase and samples. Cell Proliferation kit II (XTT), colorimetric determination, was purchased from Roche Diagnostics GmbH (Mannheim, Germany).

4.2. Instruments. An HPLC system (Spectra Physics Model SP 4400; San José, Calif., USA) coupled with a photodiode array detector Shimadzu SPD-10A (Izasa, Madrid, Spain) was used for the amino acids isolation and quantification. The analytical system consisted of a Waters ODS Spherisorb $150 \times 4.6 \mathrm{~mm}$ I.D.; $5 \mu \mathrm{m}$ packed column (Teknokroma, Barcelona, Spain) as stationary phase, preceded by a guard column Spherisorb RP-18, $5 \mu \mathrm{m}, 4 \mathrm{~mm} \times 4 \mathrm{~mm}$.

A microplate fluorescence reader FL600-BioTek spectrofluorimeter was used for the quantification of cell viability at $492 \mathrm{~nm}$.

4.3. Nigella sativa Extract. Seeds of Nigella sativa L. were supplied by the Medicinal and Aromatic Plants research Institute of Egypt (El Cairo, Egypt). Herbarium samples were authenticated by a taxonomist and a voucher specimen was deposited in the Herbarium of the Faculty of Pharmacy, 
Universidad Complutense de Madrid, with voucher number MAF 161043. The methanolic extract of the plant was prepared according to (Science and Technology Program for Development) CYTED protocol for vegetal species from countries that are included in this Program [36]. Seeds were powdered and then extracted in a soxhlet apparatus with hexane. Seeds were then extracted with methanol and kept for further studies. Methanol was completely evaporated in a rotatory evaporator under vacuum. A blackish-brown dry extract was obtained. It was kept at $4^{\circ} \mathrm{C}$ until use.

4.4. Neuronal Primary Culture. Brain neurons were obtained from foetal rat brains of 19 days of gestation as previously described [37] with minor modifications. Isolated neurons were suspended in Eagle's Minimum Essential Medium (EMEM) containing $0.3 \mathrm{~g} / \mathrm{L}$ glutamine, $0.6 \%$ glucose, $5 \%$ Phosphate Buffered Saline (PBS), 5\% Horse Serum (HS), $100 \mathrm{U} / \mathrm{mL}$ penicillin and $100 \mu \mathrm{g} / \mathrm{mL}$ streptomycin. Cells, at a density of $1 \times 10^{6}$ cells/well, were placed on plastic Petri dishes of 24 wells, treated with $10 \mu \mathrm{g} / \mathrm{mL}$ poly-Llysine to aid attachment. The plates were incubated in a humidified incubator in an atmosphere of 5\% $\mathrm{CO}_{2} / 95 \%$ air at $37^{\circ} \mathrm{C}$. After 72 hours, nonneuronal cells (contaminating glial cells) were mitotically inhibited by exposure to cytosine arabinoside. The incubation medium was replaced by fresh medium to which cytosine arabinoside was added to a final concentration of $10 \mu \mathrm{M}$.

After 3 days, this medium was replaced by fresh medium and experiments were carried out using cultures ranging from 10-15 days. Cell viability was checked by the dye exclusion method. Viability was routinely $>95 \%$. Cell purity was checked by both cells staining with cresyl violet to identify neurons and with the specific antiglial fibrillary acidic protein (GFAP) antibody to identify glial cells.

4.5. Measurement of Glial Contamination. Cortical neurons, after 7 days in culture, were detached from the culture plates with trypsin solution (0.25\% trypsin and $0.02 \%$ EDTA in Dulbecco's buffered saline without calcium and magnesium) and then the cells were fixed (during $30 \mathrm{~min}$ ) with $2 \% \mathrm{p}$ formaldehyde. After two washes with $1 \mathrm{~mL}$ of PBS, the cells were treated (during $1 \mathrm{~h}$ ) with anti-GFAP antirabbit (at dilution of 1/500). Subsequently, the cells were washed with PBS and treated with antirabbit conjugated IgG FITC, at $1 / 100$, for $30 \mathrm{~min}$. Cells were identified by flow cytometry analysis. Under these conditions, the glial cells in the cultures were $8.3 \pm 3.6 \%$ of the total (neural + glial cells).

4.6. Assessment of Cell Viability. Assessment of neuronal injury was performed with the 3-(4,5-dimethylthiazol-2-yl)2,5diphenyltetrazolium bromide (MTT) assay. This assay is used as an index of cell survival or cellular respiratory capacity-based on method of Mossmann [38] and improved by Weislow et al. [39] and Roehm et al. [40]. MTT assay is an indicator of the mitochondrial activity of living cells. The tetrazolium assay is based on the mitochondrial dehydrogenases (MD) activity and their inactivation after cell death. In live cells, MTT is reduced to a highly watersoluble orange colored product, formazan dye. Neuronal cells were seeded in 96-multiwell plates at a density of $36 \times 10^{3}$ cells/well (in $200 \mu \mathrm{L}$ medium) and kept in the incubator until 80-90\% confluence. After this, the medium was removed and the cells were washed twice with PBS and the NS extract previously dissolved in PBS was added to the wells and incubated for 15 minutes or 1 hour. After each one of the treatment periods ( 15 or $60 \mathrm{~min}$ ), the medium was removed and incubated with MTT solution (final concentration $0.3 \mathrm{mg} / \mathrm{mL}$ ), according to the kit specifications. After $2 \mathrm{~h}$ incubation at $37^{\circ} \mathrm{C}$ in a humidified atmosphere, orange dye solution was spectrophotometrically quantified using an ELISA plate reader at $492 \mathrm{~nm}$. The amount of orange formazan formed, as monitored by the absorbance, directly correlates to the number of living cells. Results are expressed as a percentage with respect to control (untreated cells). All experiments were performed in triplicate.

4.7. Measurement of the Amino Acid Secretion. HPLC analysis of amino acids was performed by a previously described method [41] with minor modifications and with the equipment and conditions that were previously developed for the amino acids determination [42]. Prior to HPLC amino acid secretion analysis cells were washed twice, at $10 \mathrm{~min}$ intervals, with $1 \mathrm{~mL}$ of Locke medium. After removing the medium, cells were stimulated for $15 \mathrm{~min}$ or 1 hour at $37^{\circ} \mathrm{C}$ with $250 \mu \mathrm{L}$ fresh Locke medium (control cells) or with $250 \mu \mathrm{L}$ of Locke medium containing the dry methanolic extract of NS seeds at different concentrations $(2.5,25$ and $250 \mu \mathrm{g} / \mathrm{mL})$.

After stimulation, the wells medium (supernatant S1) was taken for amino acid valuation and cells were then stimulated with $250 \mu \mathrm{L}$ of $60 \mathrm{mM} \mathrm{KCl}$ for $15 \mathrm{~min}$. After this, the cells secretion (supernatant S2) was removed for their valuation and cells were lysated with $250 \mu \mathrm{L}$ of distilled water for total intracellular amino acids content determination. The different supernatants obtained, S1 and S2, as well as the cell lysated, were lyophilized for their dansylation.

The content of the four amino acids present in the methanolic extract was also determined by HPLC analysis under the same conditions and these results were subtracted from the total amino acids content in cellular medium in presence of NS extract (S1) in order to obtain cellular secretion value itself.

The results were calculated as the amino acid release into the incubation medium with respect to the total amino acid content. These results were expressed as a percentage of secretion with respect to control experiments that were considered as $100 \%$.

4.8. Data Presentation. Data are presented as means \pm SEM of four separated experiments from different cell cultures, each one performed in triplicate with different batches of neuronal cells. Statistical comparisons were made using the Student's $t$-test. 


\section{References}

[1] S. M. K. Swamy and B. K. H. Tan, "Cytotoxic and immunopotentiating effects of ethanolic extract of $N$. sativa L. seeds," Journal of Ethnopharmacology, vol. 70, no. 1, pp. 1-7, 2000.

[2] K. E. El-Tahir, M. M. Ashour, and M. M. Al-Harbi, "The cardiovascular actions of the volatile oil of the black seeds (Nigella sativa) in rats: elucidation of the mechanism of action," General Pharma Cology, vol. 24, no. 5, pp. 1123-1131, 1993.

[3] A.-F. M. Abdel-Fattah, K. Matsumoto, and H. Watanabe, "Antinociceptive effects of Nigella sativa oil and its major component, thymoquinone, in mice," European Journal of Pharmacology, vol. 400, no. 1, pp. 89-97, 2000.

[4] N. Chakravarty, "Inhibition of histamine release from mast cells by nigellone," Annals of Allergy, vol. 70, no. 3, pp. 237242, 1993.

[5] M. A. Khan, "Chemical composition and medicinal properties of Nigella sativa Linn," Inflammopharmacology, vol. 7, no. 1, pp. 15-35, 1999.

[6] A. Zaoui, Y. Cherrah, M. A. Lacaille-Dubois, A. Settaf, H. Amarouch, and M. Hassar, "Diuretic and hypotensive effects of Nigella sativa on the spontaneously hypertensive rat," Therapie, vol. 55, no. 3, pp. 379-382, 2000.

[7] A. A. Al-Majed, M. H. Daba, Y. A. Asiri, O. A. Al-Shabanah, A. A. Mostafa, and H. A. El-Kashef, "Thymoquinone-induced relaxation of guinea-pig isolated trachea," Research Communications in Molecular Pathology and Pharmacology, vol. 110, no. 5-6, pp. 333-345, 2001.

[8] I. O. Farah and R. A. Begum, "Effect of Nigella sativa (N. sativa L.) and oxidative stress on the survival pattern of MCF7 breast cancer cells," Biomedical Sciences Instrumentation, vol. 39, pp. 359-364, 2003.

[9] H. S. El-Abhar, D. M. Abdallah, and S. Saleh, "Gastroprotective activity of Nigella sativa oil and its constituent, thymoquinone, against gastric mucosal injury induced by ischaemia/reperfusion in rats," Journal of Ethnopharmacology, vol. 84, no. 2-3, pp. 251-258, 2003.

[10] U. Kalus, A. Pruss, J. Bystron et al., "Effect of Nigella sativa (black seed) on subjective feeling in patients with allergic diseases," Phytotherapy Research, vol. 17, no. 10, pp. 1209$1214,2003$.

[11] M. B. Aqel, "The relaxing effect of the volatile oil of Nigella sativa seed onvascular smooth muscle," Dirasat Series B, Pure Applied Science, vol. 19, pp. 91-100, 1992.

[12] M. Reiter and W. Brandt, "Relaxant effects on tracheal and ileal smooth muscles of the guinea pig," ArzneimittelForschung/Drug Research, vol. 35, no. 1 A, pp. 408-414, 1985.

[13] A. Ilhan, A. Gurel, F. Armutcu, S. Kamisli, and M. Iraz, "Antiepileptogenic and antioxidant effects of Nigella sativa oil against pentylenetetrazol-induced kindling in mice," Neuropharmacology, vol. 49, no. 4, pp. 456-464, 2005.

[14] D. Guha, D. Biswas, and S. Purkayastha, "Suppression of penicillin-induced epileptiform activity by Nigella sativa: possible mediation by neurotransmitters," Biogenic Amines, vol. 19, no. 4-6, pp. 309-321, 2005.

[15] M. Kanter, "Protective effects of Nigella sativa on the neuronal injury in frontal cortex and brain stem after chronic toluene exposure," Neurochemical Research, vol. 33, no. 11, pp. 22412249, 2008.

[16] M. Kanter, "Nigella sativa and derived thymoquinone prevents hippocampal neurodegeneration after chronic toluene exposure in rats," Neurochemical Research, vol. 33, no. 3, pp. 579$588,2008$.
[17] M. A. U. Khan, M. K. Ashfaq, H. S. Zuberi, M. S. Mahmood, and A. H. Gilani, "The in vivo antifungal activity of the aqueous extract from Nigella sativa seeds," Phytotherapy Research, vol. 17, no. 2, pp. 183-186, 2003.

[18] H. Hosseinzadeh and S. Parvardeh, "Anticonvulsant effects of thymoquinone, the major constituent of Nigella sativa seeds, in mice," Phytomedicine, vol. 11, no. 1, pp. 56-64, 2004.

[19] M. S. Al-Jassir, "Chemical composition and microflora of black cumin (Nigella sativa L.) seeds growing in Saudi Arabia," Food Chemistry, vol. 45, no. 4, pp. 239-242, 1992.

[20] T. Perveen, S. Haider, S. Kanwal, and D. J. Haleem, "Repeated administration of Nigella sativa decreases 5-HT turnover and produces anxiolytic effects in rats," Pakistan Journal of Pharmaceutical Sciences, vol. 22, no. 2, pp. 139-144, 2009.

[21] H. Hosseinzadeh, S. Parvardeh, M. Nassiri-Asl, and M.-T. Mansouri, "Intracerebroventricular administration of thymoquinone, the major constituent of Nigella sativa seeds, suppresses epileptic seizures in rats," Medical Science Monitor, vol. 11, no. 4, pp. BR106-BR110, 2005.

[22] S. S. Muthu Kumara and B. T. Kwong Huat, "Extraction, isolation and characterisation of antitumor principle, $\alpha$ hederin, from the seeds of Nigella sativa," Planta Medica, vol. 67, no. 1, pp. 29-32, 2001.

[23] Atta-ur-Rahman, S. Malik, S. Sadiq Hasan, M. Iqbal Choudhary, C.-Z. Ni, and J. Clardy, "Nigellidine-a new indazole alkaloid from the seeds of Nigella sativa," Tetrahedron Letters, vol. 36, no. 12, pp. 1993-1996, 1995.

[24] I. Merfort, V. Wray, H. H. Barakat, S. A. M. Hussein, M. A. M. Nawwar, and G. Willuhn, "Flavonol triglycosides from seeds of Nigella sativa," Phytochemistry, vol. 46, no. 2, pp. 359-363, 1997.

[25] M. F. Ramadan and J. T. Mörsel, "Characterization of phospholipid composition of black cumin (Nigella sativa L.) seed oil," Nahrung, vol. 46, no. 4, pp. 240-244, 2002.

[26] T. B. Al-Naggar, M. P. Gómez-Serranillos, M. E. Carretero, and A. M. Villar, "Neuropharmacological activity of Nigella sativa L. extracts," Journal of Ethnopharmacology, vol. 88, no. 1, pp. 63-68, 2003.

[27] M. S. Santos, F. Ferreira, A. P. Cunha, A. P. Carvalho, C. F. Ribeiro, and T. Macedo, "Synaptosomal GABA release as influenced by valerian root extract-involvement of the GABA carrier," Archives Internationales de Pharmacodynamie et de Therapie, vol. 327, no. 2, pp. 220-231, 1994.

[28] R. Awad, J. T. Arnason, V. Trudeau et al., "Phytochemical and biological analysis of skullcap (Scutellaria lateriflora L.): a medicinal plant with anxiolytic properties," Phytomedicine, vol. 10, no. 8, pp. 640-649, 2003.

[29] G. Levi and M. Raiteri, "Carrier-mediated release of neurotransmitters," Trends in Neurosciences, vol. 16, no. 10, pp. 415419, 1993.

[30] L. Raiteri, S. Stigliani, L. Zedda, M. Raiteri, and G. Bonanno, "Multiple mechanisms of transmitter release evoked by 'pathologically' elevated extracellular $[\mathrm{K}+]$ : involvement of transporter reversal and mitochondrial calcium," Journal of Neurochemistry, vol. 80, no. 4, pp. 706-714, 2002.

[31] D. R. Buckle, J. R. S. Arch, N. E. Bowring et al., "Relaxant effects of the potassium channel activators BRL 38227 and pinacidil on guinea-pig and human airway smooth muscle, and blockade of their effects by glibenclamide and BRL 31660," Pulmonary Pharmacology, vol. 6, no. 1, pp. 77-86, 1993.

[32] A. H. Gilani, N. Aziz, I. M. Khurram, K. S. Chaudhary, and A. Iqbal, "Bronchodilator, spasmolytic and calcium antagonist 
activities of Nigella sativa seeds (Kalonji): a traditional herbal product with multiple medicinal uses," Journal of the Pakistan Medical Association, vol. 51, no. 3, pp. 115-120, 2001.

[33] M. H. Boskabady, M. N. Shafei, and H. Parsaee, "Effects of aqueous and macerated extracts from Nigella sativa on guinea pig isolated heart activity," Pharmazie, vol. 60, no. 12, pp. $943-$ 948, 2005.

[34] M. H. Boskabady, B. Shirmohammadi, P. Jandaghi, and S. Kiani, "Possible mechanism(s) for relaxant effect of aqueous and macerated extracts from Nigella sativa on tracheal chains of guinea pig," BMC Pharmacology, vol. 4, article 3, 2004.

[35] M. H. Boskabady and B. Shirmohammadi, "Effect of Nigella sativa on isolated guinea pig trachea," Archives of Iranian Medicine, vol. 5, no. 2, pp. 103-107, 2002.

[36] "CYTED: Programa Iberoamericano de Ciencia y Tecnología para el Desarrollo," Manual de Técnicas de Investigación, 1993.

[37] M. Segal, "Rat hippocampal neurons in culture: responses to electrical and chemical stimuli," Journal of Neurophysiology, vol. 50, no. 6, pp. 1249-1264, 1983.

[38] T. Mosmann, "Rapid colorimetric assay for cellular growth and survival: application to proliferation and cytotoxicity assays," Journal of Immunological Methods, vol. 65, no. 1-2, pp. 55-63, 1983.

[39] O. S. Weislow, R. Kiser, D. L. Fine, J. Bader, R. H. Shoemaker, and M. R. Boyd, "New soluble-formazan assay for HIV1 cytopathic effects: application to high-flux screening of synthetic and natural products for AIDS-antiviral activity," Journal of the National Cancer Institute, vol. 81, no. 8, pp. 577586, 1989.

[40] N. W. Roehm, G. H. Rodgers, S. M. Hatfield, and A. L. Glasebrook, "An improved colorimetric assay for cell proliferation and viability utilizing the tetrazolium salt XTT," Journal of Immunological Methods, vol. 142, no. 2, pp. 257-265, 1991.

[41] F. J. Márquez, A. R. Quesada, F. Sánchez-Jiménez, and I. Núñez de Castro, "Determination of 27 dansyl amino acid derivatives in biological fluids by reversed-phase high-performance liquid chromatography," Journal of Chromatography-Biomedical Applications, vol. 380, no. 2, pp. 275-283, 1986.

[42] M. V. Naval, M. P. Gómez-Serranillos, M. E. Carretero, and C. De Arce, "Value of high-performance liquid chromatographic analysis of amino acids in the determination of Panax ginseng radix extract effect in cultured neurons," Journal of Chromatography A, vol. 1121, no. 2, pp. 242-247, 2006. 

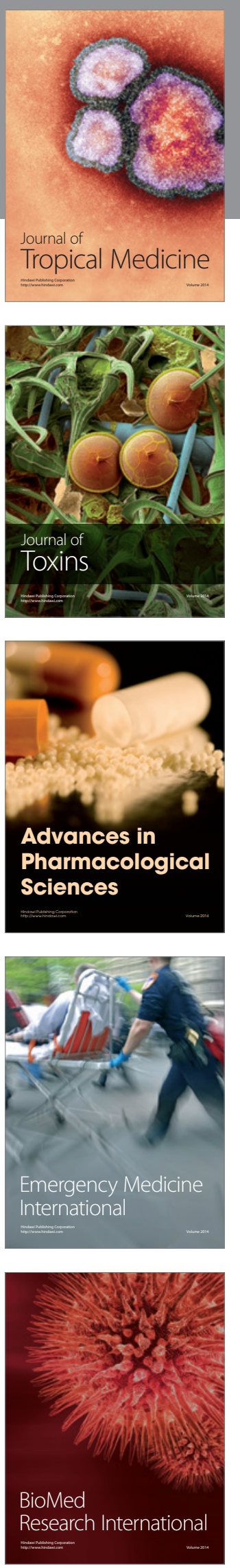
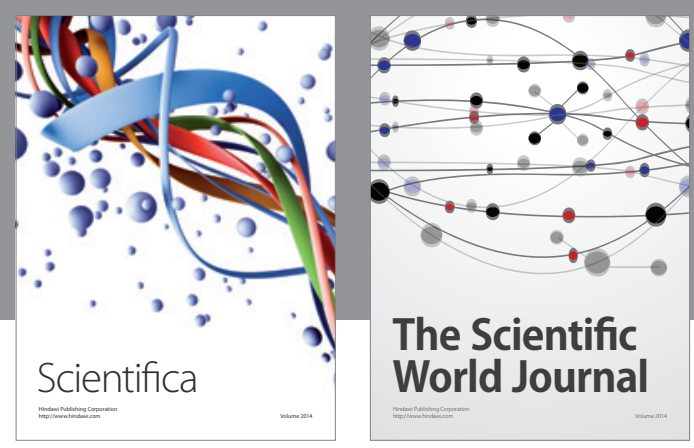

The Scientific World Journal
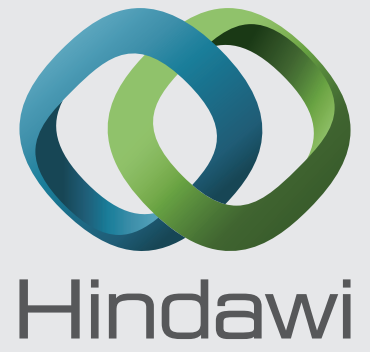

Submit your manuscripts at

http://www.hindawi.com
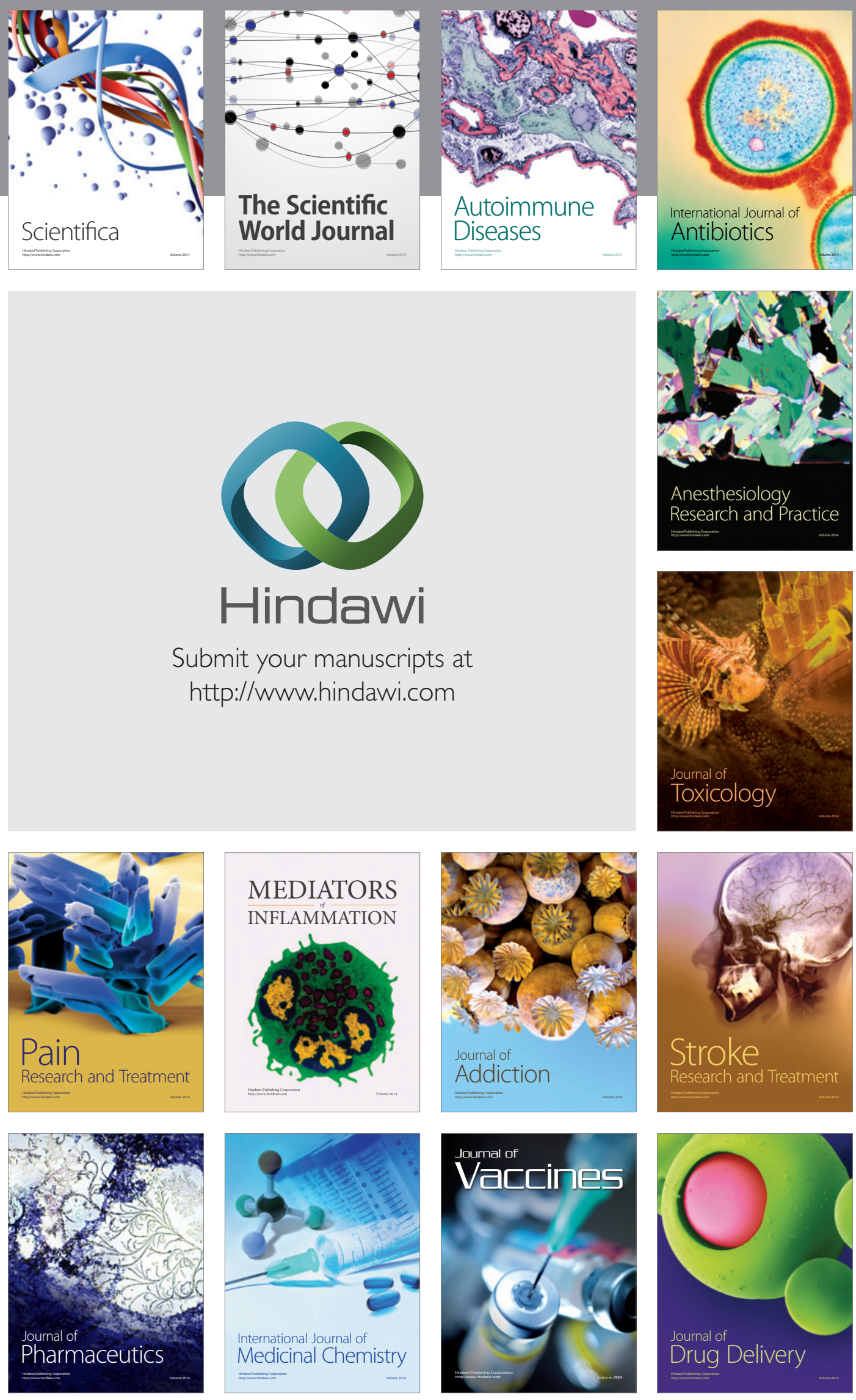